\title{
Communication \\ Development of an UPLC-MS/MS Method for Quantitative Analysis of Clotrimazole in Human Plasma Samples
}

\author{
Lucia Lisi *, Gabriella Maria Pia Ciotti and Pierluigi Navarra \\ Dipartimento di Sicurezza e Bioetica Sezione di Farmacologia, Università Cattolica Del Sacro Cuore, \\ Largo F Vito, 100168 Roma, Italy; gabriella.ciotti@hotmail.it (G.M.P.C.); pierluigi.navarra@unicatt.it (P.N.) \\ * Correspondence: lucia.lisi@unicatt.it
}

Received: 21 July 2020; Accepted: 21 September 2020; Published: 16 November 2020

\begin{abstract}
An ultra-performance liquid chromatography-tandem mass spectrometry method was developed for the quantification of clotrimazole (CTZ) plasma levels after intravaginal administration of the drug given at approved dosages. Plasma samples were extracted by liquid-liquid extraction and a single chromatographic run could be completed within about $2 \mathrm{~min}$. The method was linear over the investigated range $(0.488-250 \mathrm{ng} / \mathrm{mL})$ with all the correlation coefficients, $\mathrm{R}^{2}$, greater than 0.9903. All data were in the range of $\pm 15.0 \%$ with respect to the nominal concentration for high QC and medium QC, and in the range $\pm 20 \%$ with respect to the nominal concentration for low QC. This rapid and sensitive method was validated and could be applied to human plasma samples from a healthy volunteer, showing that the assay is able to detect plasma concentrations of CTZ in the range of those found after the administration of the drug at approved dosages in the clinical setting.
\end{abstract}

Keywords: clotrimazole; plasma; UPLC/MS-MS; bioequivalence; intravaginal treatment

\section{Introduction}

Clotrimazole (CTZ) is a well-known imidazole derivative primarily used for local treatment of vaginal and skin infections due to yeasts and dermatophytes, especially candida spp. [1]. CTZ was initially tested for systemic use in candidal septicemia, urinary and pulmonary candidiasis or in other types of serious fungal infections, including pulmonary aspergillosis, where the drug was given orally. This use was abandoned, mostly because of the high incidence of gastro-intestinal disturbances and neurological reactions [1]. CTZ is currently used in skin infections caused by Candida or dermatophytes. CTZ cream showed similar efficacy compared to tolnaftate in the treatment of dermatophytoses, and was as effective as nystatin in cutaneous candidiasis [1]. CTZ absorption through the skin is thought to be minimal, with peak serum concentrations below the detection limit of $0.001 \mu \mathrm{g} / \mathrm{mL}$ [2]. In the treatment of vaginal candidiasis, CTZ vaginal tablets and cream obtained cure rates comparable with those of nystatin [1]. Likewise, the absorption of CTZ after vaginal application is estimated to be very low, ranging between 3 and $10 \%$ of the dose administered [3].

A well-established medicinal product, CTZ has long been out of patent; therefore, the active ingredient is suitable for the development of generic drugs. This fact normally prompts the development of good-laboratory-practice (GLP)-level analytical methods supporting the bioequivalence (BE) studies required for generic drug approval. This did not seem to be the case with CTZ, most probably because BE studies are not required for locally applied and locally acting products [4].

In fact, most recent reports of analytical methods developed to measure plasma CTZ levels rely on the high-performance liquid chromatography (HPLC) approach for CTZ detection, and the detection limit reported is not lower than $50 \mathrm{ng} / \mathrm{mL}[5,6]$. Conversely, peak CTZ plasma levels are reported to be 
30 and $10 \mathrm{ng} / \mathrm{mL}$, respectively, $24 \mathrm{~h}$ after the intravaginal administration of a $100 \mathrm{mg}$ tablet or a cream containing $50 \mathrm{mg}$ of the drug [7]. Thus, based on the above data, the issue of CTZ determination in biological fluids emerges as a somewhat neglected area of bioanalytical research.

With this is in mind, in this work we developed a fast, inexpensive ultra-performance liquid chromatography (UPLC)-tandem mass spectrometry method for the quantification of CTZ in human plasma. The important novelty of our rapid method is given by the possibility of dosing in the plasma of patients who have received CTZ up to $500 \mathrm{pg} / \mathrm{mL}$ of the drug, thus measuring very low concentrations that can derive from partial systemic absorption after vaginal or cutaneous administration.

To date, the need of a highly sensitive assay method for CTZ (a drug out of patent and therefore suitable for the development of generic drug) assessment has been limited, because the bioequivalence (BE) studies required for generic drug approval are not required for locally applied and locally acting products. However, it might be foreseen that the regulatory scenario will change for BE studies on CTZ.

\section{Materials and Methods}

\subsection{Drugs and Administration}

The powder of CTZ used for calibration standard and quality control samples was purchased by SIGMA; CTZ for healthy volunteer administration was Bayer $2 \%$ clotrimazole cream (Gyno-Canesten ${ }^{\circledR}$ batch \#BXPJSK2 and \#GP01W1N). One healthy volunteer (a woman of 39 years old) received a $5 \mathrm{~g}$ intravaginal dose of $2 \%$ clotrimazole cream (Gyno-Canesten ${ }^{\circledR}$ ), corresponding to $100 \mathrm{mg}$ of CTZ. The volunteer gave her informed consent. The volunteer self-administered the drug twice: on day 0 and after 21 days (day 21) from the first administration. The day after administration, blood was collected in the EDTA tube. All subjects gave their informed consent for inclusion before they participated in the study. The study was conducted in accordance with the Declaration of Helsinki, and the protocol was approved by the Ethics Committee of Il Comitato Etico (N. 0190157/2020).

\subsection{Preparation of Stock Solution, Calibration Standard and Quality Control Samples}

Stock solutions of CTZ were prepared by dissolving accurately weighed amounts of the drug in $\mathrm{MeOH}$ to obtain a final concentration of $0.1 \mathrm{mg} / \mathrm{mL}$. Stock solutions were stored at $4{ }^{\circ} \mathrm{C}$. Calibration standards were freshly prepared the day of the assay by diluting stock solutions of CTZ in drug-free human plasma to yield CTZ concentrations of 250, 125, 62.5, 31.25, 15.635, 7.813, 3.906, 1.953, $0.977,0.488 \mathrm{ng} / \mathrm{mL}$. Three quality control (QC) samples or spiked samples were obtained by dilution of the stock solutions of CTZ in blank plasma at the high, medium, and low concentrations of CTZ, i.e., 250, 100 and $25 \mathrm{ng} / \mathrm{mL}$, respectively. Aliquots of spiked samples were kept at 4 or $-20{ }^{\circ} \mathrm{C}$ and thawed on the day of analysis.

\subsection{Clotrimazole Liquid/Liquid Extraction from Plasma Samples}

Liquid/liquid extraction was used for the purification and concentration of CTZ from plasma samples. In the method used, briefly, a $100-\mu \mathrm{L}$ aliquot of plasma was added to $50 \mu \mathrm{L}$ of $\mathrm{H}_{2} \mathrm{O} / \mathrm{AcN}$ $(50: 50, v / v)$ and then to $200 \mu \mathrm{L}$ of ACN. After a rapid ( $2 \mathrm{~min}$ ) vortex mixing, the mixture was centrifuged at $3000 \mathrm{rpm}$ for $10 \mathrm{~min}$ at room temperature. The upper organic layer (about $250 \mu \mathrm{L}$ ) was separated and evaporated to dryness at $40{ }^{\circ} \mathrm{C}$ (normally $80 \mathrm{~min}$ ). The residue was then reconstituted in $70 \mu \mathrm{L}$ of $\mathrm{MEOH}$. A $5 \mu \mathrm{L}$ aliquot of each sample was injected into the UPLC-MS/MS system for analysis.

\subsection{Chromatographic and Mass-Spectrometric Conditions}

The chromatographic separation was performed on an AQUITY UPLC system (Waters Corp., Milford, MA, USA) with cooled auto-sampler and column oven for temperature control. An AQUITY UPLC BEH C18 column (1.7 $\mu \mathrm{m} ; 2.1 \times 50 \mathrm{~mm}$; Waters Corp., Milford, MA, USA) was employed, and the column temperature was maintained at $40{ }^{\circ} \mathrm{C}$. The elution was performed at a flow rate of $0.1 \mathrm{~mL} / \mathrm{min}$ with a run time of $2 \mathrm{~min}$ and then a flow rate of $0.7 \mathrm{~mL} / \mathrm{min}$ for another $1 \mathrm{~min}$. 
Mobile phases were constituted by a mixture of 18:82 of: Phase $\mathrm{A}\left(\mathrm{H}_{2} \mathrm{O}+\right.$ Ammonium Acetate $0.2 \%+$ $\mathrm{HCOOH} 0.1 \%$ ) and Phase $\mathrm{B}(\mathrm{MeOH})$. The UPLC was connected to a triple quadrupole tandem mass detector (TQD) (Waters Corp., Milford, MA, USA) with an electrospray ionization (ESI) source for the mass spectrometric detection. The ESI source was set in positive ion mode and the quantification was performed using multi-reaction monitoring (MRM) mode for the most suitable mass transitions. The quantitative transition was from 277.1 to $165.2 \mathrm{~m} / \mathrm{z}$ at collision energy set to $27 \mathrm{~V}$ and the confirmatory transition was from 277.1 to $242.2 \mathrm{~m} / z$ at collision energy set to $28 \mathrm{~V}$ [8]. The optimal MS parameters are showed in Table 1. Data were processed using MassLynx software with a TargetLynx program version 4.1 (Waters Corp., Milford, MA, USA).

Table 1. The optimal MS parameters for plasma determination of clotrimazole (CTZ).

\begin{tabular}{lc}
\hline Source (ESI+) and Analyzer (SI+) and & Settings \\
\hline Capillary voltage $(\mathrm{Kv})$ & 4.0 \\
Cone voltage $(\mathrm{V})$ & 40.0 \\
Extractor $(\mathrm{V})$ & 3.0 \\
Source temperature $\left({ }^{\circ} \mathrm{C}\right)$ & 150 \\
Desolvation temperature $\left({ }^{\circ} \mathrm{C}\right)$ & 250 \\
Cone gas flow $(\mathrm{L} / \mathrm{h})$ & 1 \\
Desolvation gas flow $(\mathrm{L} / \mathrm{h})$ & 500 \\
Collision energy $(\mathrm{eV})$ & 27.0 \\
\hline
\end{tabular}

\section{Results}

\subsection{UPLC/MS-MS Chromatograms}

Under the above-described chromatographic conditions, the retention time for CTZ was $2.07 \mathrm{~min}$. Figure 1 shows representative chromatograms of two different ion transition $\mathrm{m} / \mathrm{z} 277.1$ to 165.1 and $\mathrm{m} / \mathrm{z} 277.1$ to 242.2 obtained from the high-concentration QC $(250 \mathrm{ng} / \mathrm{mL} \mathrm{CTZ})$.

(A)

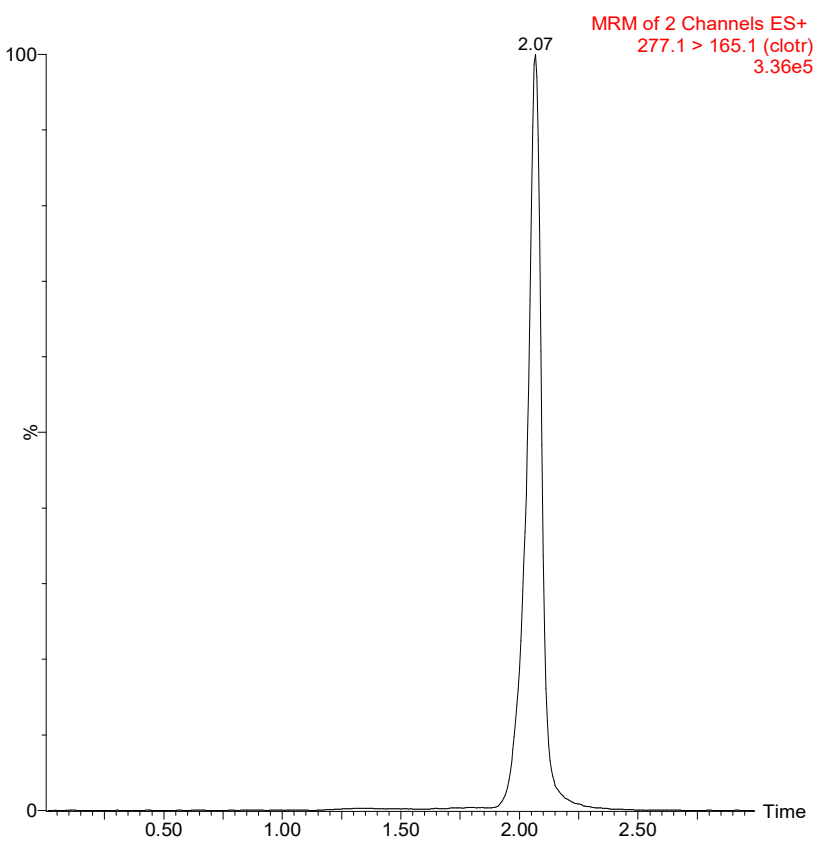

Figure 1. Cont. 
(B)

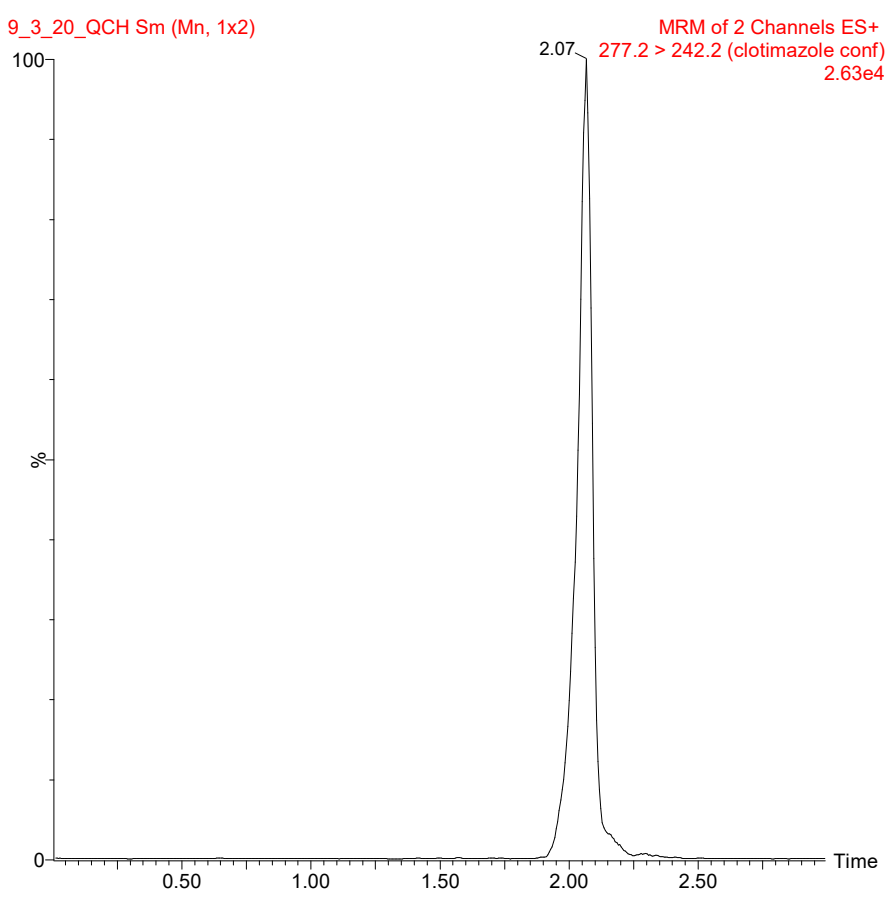

Figure 1. Representative chromatograms obtained from the high concentration of spiked sample and two different transitions. (A) Chromatogram of (250 ng/mL), transition $277.1>165.1 \mathrm{~m} / \mathrm{z}$ (B) Chromatogram of $(250 \mathrm{ng} / \mathrm{mL})$, transition $277.1>242.2 \mathrm{~m} / \mathrm{z}$.

Figure 2 shows a chromatogram obtained from a blank plasma. CTZ was well separated from the other detectable components at the selected wavelength. Comparing the mean areas of post-extraction spiked plasma samples with the neat standard solution at the same concentration, no significant matrix effect was observed. The last point of calibration curve, shown in Figure 3, was $0.488 \mathrm{ng} / \mathrm{mL}$.

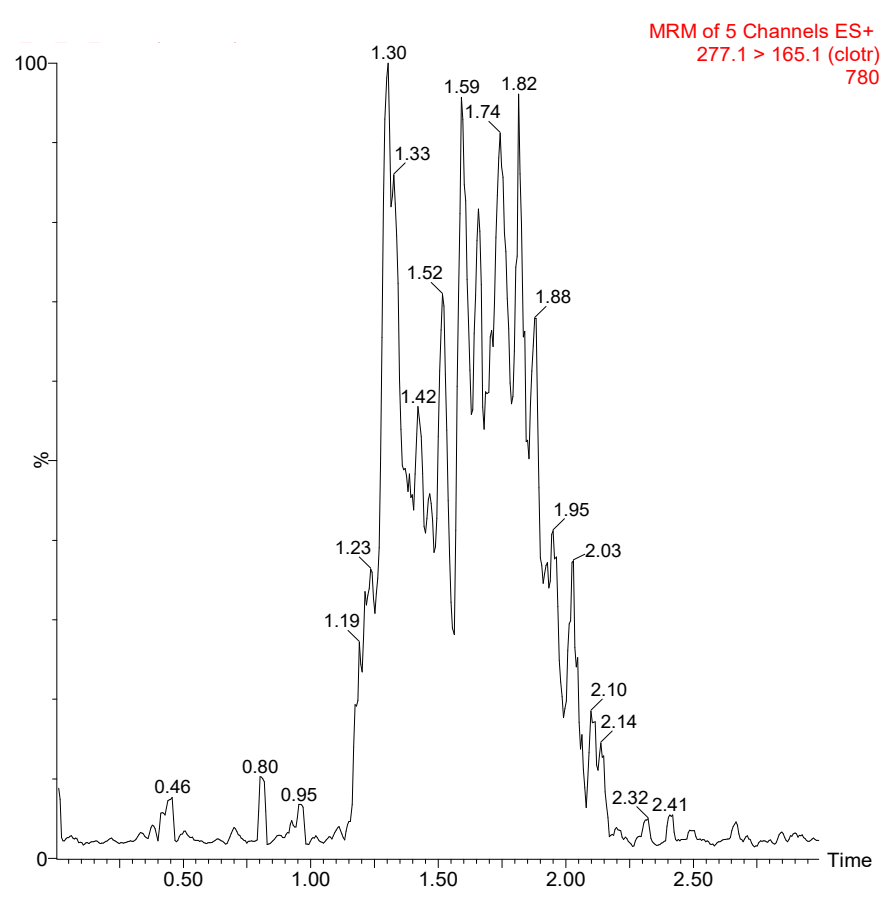

Figure 2. Chromatogram obtained from a blank plasma sample. 


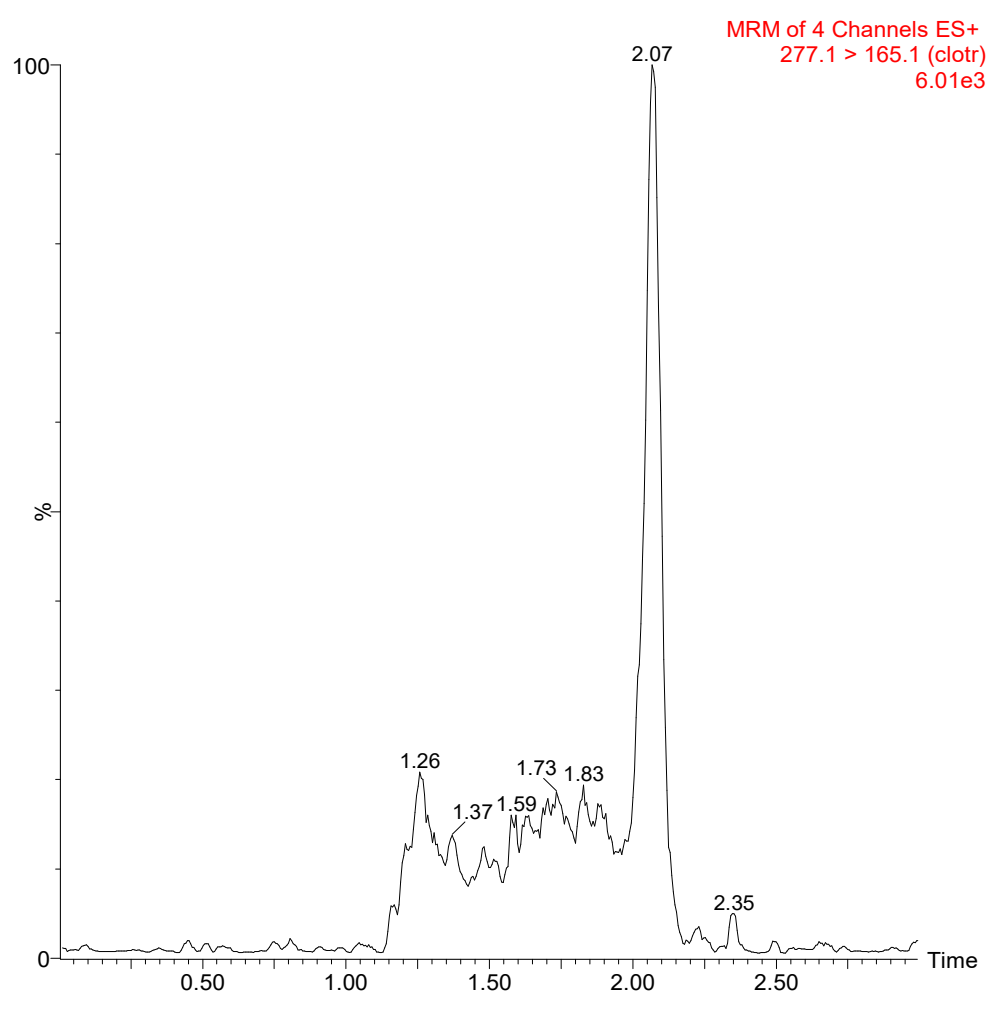

Figure 3. Chromatogram indicating $0.488 \mathrm{ng} / \mathrm{mL}$ of CTZ in plasma sample.

\subsection{Validation}

Calibration curves of CTZ appeared linear over the studied concentration range of $250-0.49 \mathrm{ng} / \mathrm{mL}$, which covers the expected plasma concentrations commonly found in plasma [5], with a medium correlation coefficient $\mathrm{R}^{2}$ of 0.9903 (Figure 4 ).

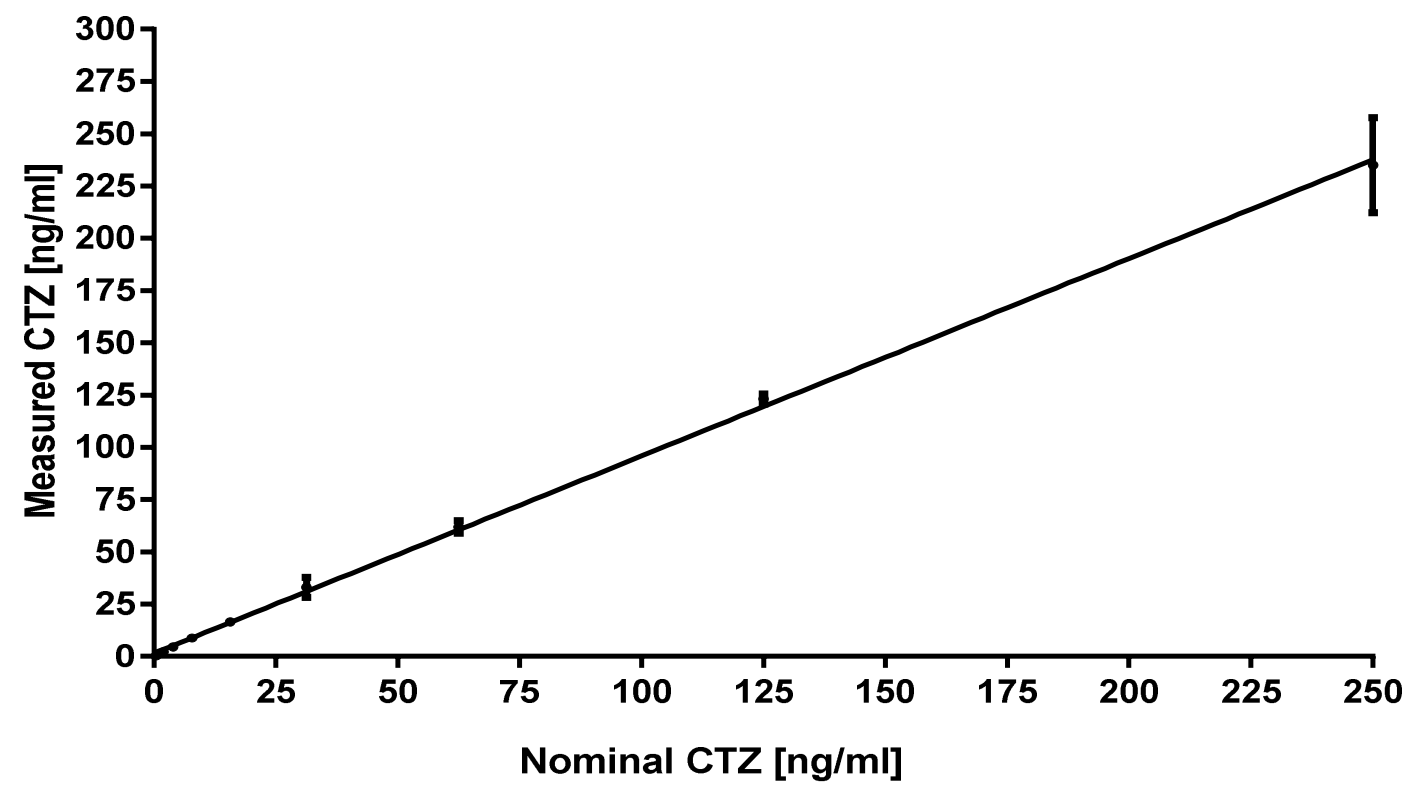

Figure 4. Calibration curve of CTZ. 
Table 2 shows all the major parameters studied for the validation of the method. LOD was calculated as three times the standard deviation of plasma blank, while LOQ was 10 times the standard deviation of plasma blank.

Table 2. Validation parameters.

\begin{tabular}{cc}
\hline Intraday CV & $7.80 \%$ \\
Inter-day CV & $2.88 \%$ \\
LOD & $0.135 \mathrm{ng} / \mathrm{mL}$ \\
LOQ & $0.450 \mathrm{ng} / \mathrm{mL}$ \\
Range of linearity & $0.488-250 \mathrm{ng} / \mathrm{mL}$ \\
Equation & $\mathrm{Y}=0.9436^{*} \mathrm{X}+1.537$ \\
$\mathrm{R}^{2}$ & 0.9903 \\
CV intra-subject & $11.34 \%$ \\
\hline
\end{tabular}

In Table 3, the results of three different measures of spiked samples were reported. In particular, the samples were measured after extraction, after keeping them for a month at $4{ }^{\circ} \mathrm{C}$ and after keeping them for a month at $-20{ }^{\circ} \mathrm{C}$. All observed data were in the range of $\pm 15.0 \%$ with respect to the nominal concentration for high and medium spiked samples, and in the range $\pm 20 \%$ with respect to the nominal concentration for the low spiked sample. Therefore, as established by the FDA guideline for Bioanalytical Method Validation [9], and fully discussed in the paper of Kaza and collaborators [10], this method achieved a degree of reproducibility and accuracy high enough for the determination of CTZ.

Table 3. The results of three different measures of spiked samples.

\begin{tabular}{|c|c|c|c|c|c|c|}
\hline \multirow[t]{2}{*}{$\begin{array}{l}\text { Time of Spiked } \\
\text { Samples Measure }\end{array}$} & \multirow{4}{*}{$\begin{array}{c}\begin{array}{c}\text { Nominal } \\
\text { Concentration } \\
{[\mathrm{ng} / \mathrm{mL}]}\end{array} \\
250 \\
\end{array}$} & \multirow{4}{*}{$\begin{array}{c}\text { [ng/mL] } \\
220.2 \\
221.1 \\
227.5\end{array}$} & \multicolumn{2}{|c|}{$\begin{array}{c}\text { Mean } \\
{[\mathrm{ng} / \mathrm{mL}]} \\
\pm \mathrm{SD}(\mathrm{N})\end{array}$} & \multirow{4}{*}{$\begin{array}{c}\text { \% Deviation Respect the } \\
\text { Nominal Concentration } \\
-11.9 \\
-11.6 \\
-9\end{array}$} & \multirow{4}{*}{$\begin{array}{c}\text { Mean \% } \\
\text { Deviation } \\
-10.8\end{array}$} \\
\hline & & & $222.9 \pm$ & $4.0(3)$ & & \\
\hline \multirow{8}{*}{ After extraction } & & & & & & \\
\hline & & & & & & \\
\hline & & 104.4 & $105.0 \pm$ & $4.5(3)$ & 4.4 & \\
\hline & 100 & 101.7 & & & 1.7 & 5.5 \\
\hline & & 110.4 & & & 10.4 & \\
\hline & & 27.7 & $28.5 \pm$ & $0.8(3)$ & 10.7 & \\
\hline & 25 & 28.5 & & & 14.1 & 13.8 \\
\hline & & 29.2 & & & 16.7 & \\
\hline \multirow{9}{*}{$\begin{array}{l}\text { After keeping at } \\
4^{\circ} \mathrm{C}\end{array}$} & & 200.6 & $205.5 \pm$ & $7.3(3)$ & -19.8 & \\
\hline & 250 & 213.8 & & & -14.5 & -17.8 \\
\hline & & 202.0 & & & -19.2 & \\
\hline & & 99.1 & $105.8 \pm$ & $5.9(3)$ & -0.9 & \\
\hline & 100 & 110.5 & & & 10.5 & 5.6 \\
\hline & & 107.1 & & & 7.1 & \\
\hline & & 30.9 & $30.1 \pm$ & $0.7(3)$ & 23.7 & \\
\hline & 25 & 29.7 & & & 18.8 & 20.4 \\
\hline & & 29.7 & & & 18.7 & \\
\hline \multirow{9}{*}{$\begin{array}{l}\text { After keeping at } \\
\qquad-20^{\circ} \mathrm{C}\end{array}$} & & 276.1 & \multirow{3}{*}{\multicolumn{2}{|c|}{$259.1 \pm 15.8$ (3) }} & 10.4 & \\
\hline & 250 & 256.6 & & & 2.6 & 3.6 \\
\hline & & 244.7 & & & -2.1 & \\
\hline & & 103.1 & $98.9 \pm$ & $6.4(3)$ & 3.1 & \\
\hline & 100 & 101.3 & & & 1.3 & -1.4 \\
\hline & & 91.3 & & & -8.7 & \\
\hline & & 32.9 & $29.1 \pm$ & $3.4(3)$ & 31.8 & \\
\hline & 25 & 27.5 & & & 9.9 & 16.3 \\
\hline & & 26.8 & & & 7.2 & \\
\hline
\end{tabular}


In addition, the differences between the fresh and stored spiked samples are also in the range of $\pm 20 \%$. In particular, the differences between freshly prepared spiked samples and $4{ }^{\circ} \mathrm{C}$ spiked samples were $+7.83 \%$ at $250 \mathrm{ng} / \mathrm{mL},-0.06 \%$ at $100 \mathrm{ng} / \mathrm{mL},-5.72 \%$ at $25 \mathrm{ng} / \mathrm{mL}$. The differences between freshly prepared spiked samples and $-20{ }^{\circ} \mathrm{C}$ QCs were $-16.23 \%$ at $250 \mathrm{ng} / \mathrm{mL},+6.56 \%$ at $100 \mathrm{ng} / \mathrm{mL},-2.11 \%$ at $25 \mathrm{ng} / \mathrm{mL}$.

\subsection{In Vivo Testing}

One healthy volunteer (a woman of 39 years old) received a 5-g intravaginal dose of $2 \%$ clotrimazole cream (Gyno-Canesten ${ }^{\circledR}$ ), corresponding to $100 \mathrm{mg}$ of CTZ, at Day-0. After $24 \mathrm{~h}$ (at the time of peak plasma levels [5]), blood was collected, and CTZ plasma levels were measured. We found $28.7 \pm 4.5 \mathrm{ng} / \mathrm{mL}$ of plasma (the mean $\pm \mathrm{SD}$ of six replicates). Drug administration, at the same dose as above, was repeated at Day-21, and a blood sample was collected $24 \mathrm{~h}$ later. CTZ plasma levels from the repeated dosing were $24.4 \pm 2.2 \mathrm{ng} / \mathrm{mL}$ of plasma (the mean $\pm \mathrm{SD}$ of six replicates). Figure 5 shows a representative peak from healthy volunteer. The intra-subject coefficient of variations were $11.34 \%$.

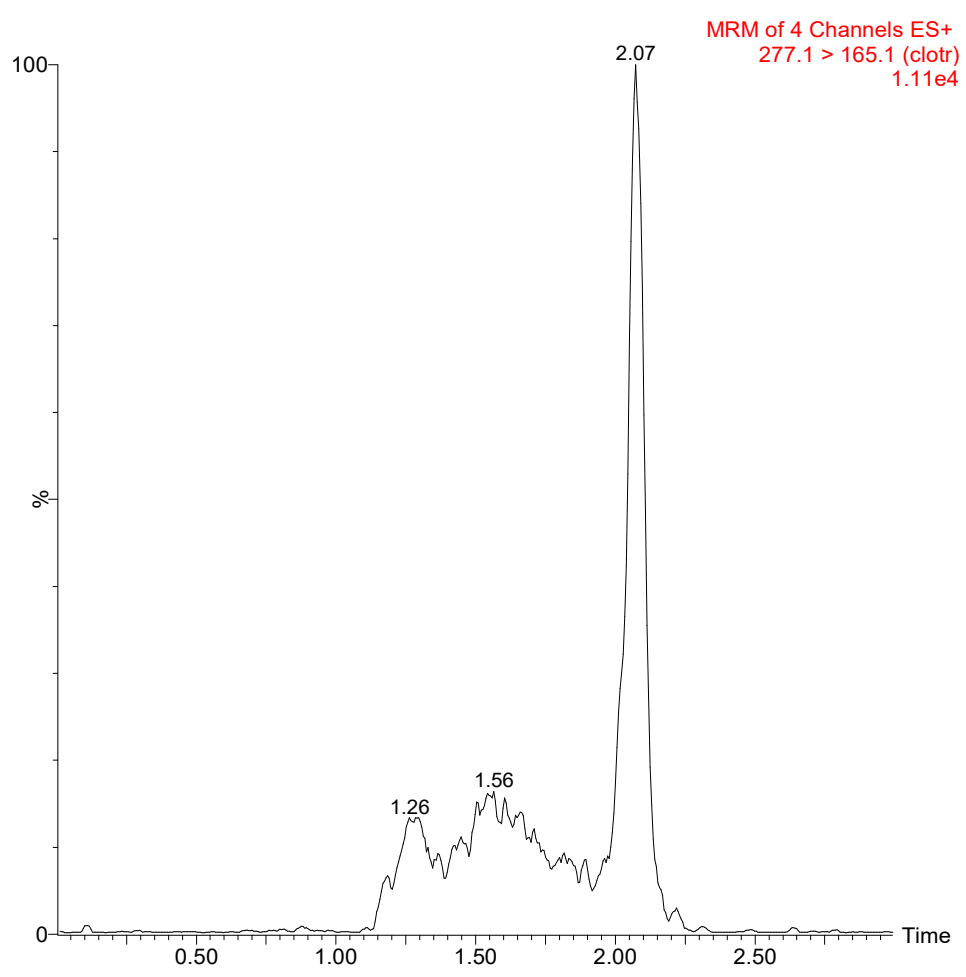

Figure 5. Representative peaks from one healthy volunteer obtained $24 \mathrm{~h}$ after day- 0 administration of CTZ.

\section{Discussion}

Here, we describe an UPLC-MS/MS-based analytical method to determine the plasma levels of CTZ. With a detection limit $\approx 500 \mathrm{pg} / \mathrm{mL}$ and linear calibration curves in the range of $250-0.49 \mathrm{ng} / \mathrm{mL}$, this assay is able to detect plasma concentrations of CTZ in the range of those found after the administration of the drug at approved dosages in the clinical setting [7]. To our knowledge, this is the first published method achieving such a low level of performance. In fact, two recently reported methods based on the HPLC approach were able to detect CTZ in the concentration range $0.05-5 \mu \mathrm{g} / \mathrm{mL}$ [5], or in the range $0.1-8 \mu \mathrm{g} / \mathrm{mL}[6]$. Another less recent method reported a detection limit of $0.1 \mu \mathrm{Mol} / \mathrm{L}$, corresponding to about $33.4 \mu \mathrm{g} / \mathrm{L}$ [11]. In addition, there are other published methods measuring CTZ in different solutions [12] or monitoring the degradation pathway of CTZ [13], but the measure of drug concentration is in the microgram range. 
Our UPLC-MS/MS method involves non-expensive liquid/liquid extraction. The choice of conditions comes from a thorough study of the literature. In particular, a readjustment of the CTZ and HZ08 extraction conditions of Yan F and collaborators was implemented [14,15]. In the methods of Yan F, CTZ was used as an internal standard [14].

According to other HPLC methods [16,17], our method uses a column temperature of $40{ }^{\circ} \mathrm{C}$. In addition, according to the stability study of Patricia Garcia Ferreira group [18], the sample of CTZ was dried at $40^{\circ} \mathrm{C}$.

Apart from HPLC-based methods, CTZ in plasma and other biological fluids was also measured by quantitative thin-layer chromatography, allowing to detect fungicidal CTZ concentrations in vaginal fluids, in contrast to CTZ plasma levels lower than $0.01 \mu \mathrm{g} / \mathrm{mL}$ [3]. By comparing the detection limits of these methods with the range of plasma concentration expected after the intravaginal administration of CTZ given according to SmPC dosages, it emerges that previous methods would fall short when assessing CTZ plasma levels under these conditions.

In addition, the method underway in MRM mode can measure different analytes and, with an RT of 2.07, CTZ measurement takes place in a very short time.

The need of a highly sensitive and rapid assay method for CTZ assessment has been limited to date, because of the reasons discussed in the Introduction section. However, it might be foreseen that the regulatory scenario will change for BE studies on CTZ. In fact, the new EMA guideline on the quality and equivalence of topical products, which is currently in its draft version and has not come into force, in Section 5.3.1, introduces the possibility of performing pharmacokinetic BE studies for these products [19]. In this regard, the draft states that "human bioequivalence studies are appropriate when the active substance has quantifiable systemic bioavailability" [19].

Author Contributions: Conceptualization, L.L. and P.N.; validation, G.M.P.C.; formal analysis L.L.; investigation, G.M.P.C., L.L.; writing-review and editing, L.L. and P.N. All authors have read and agreed to the published version of the manuscript.

Funding: This research was funded by Fondi Ateneo 2019 to P.N.

Conflicts of Interest: The authors declare no conflict of interest.

Ethical Statement: The healthy volunteer gave her informed consent for inclusion before she participated in the study. The study was conducted in accordance with the Declaration of Helsinki.

\section{References}

1. Sawyer, P.R.; Brogden, R.N.; Pinder, R.M.; Speight, T.M. Avery, G.S. Clotrimazole: A review of its antifungal activity and therapeutic efficacy. Drugs 1975, 9, 424-447. [CrossRef] [PubMed]

2. Available online: https://www.medicines.org.uk/emc/product/2598/smpc (accessed on 22 September 2020).

3. Ritter, W.; Patzschke, K.; Krause, U.; Stettendorf, S. Pharmacokinetic fundamentals of vaginal treatment with clotrimazole. Chemotherapy 1982, 28 (Suppl. 1), 37-42. [CrossRef] [PubMed]

4. Available online: https://www.ema.europa.eu/en/documents/scientific-guideline/note-guidance-clinicalrequirements-locally-applied-locally-acting-products-containing-known_en.pdf (accessed on 22 September 2020).

5. Campestre, C.; Locatelli, M.; Guglielmi, P.; De Luca, E.; Bellagamba, G.; Menta, S.; Zengin, G.; Celia, C.; Di Marzio, L.; Carradori, S. Analysis of imidazoles and triazoles in biological samples after MicroExtraction by packed sorbent. J. Enzym. Inhib. Med. Chem. 2017, 32, 1-11. [CrossRef] [PubMed]

6. Locatelli, M.; Kabir, A.; Innosa, D.; Lopatriello, T.; Furton, K.G. A fabric phase sorptive extraction-High performance liquid chromatography-Photo diode array detection method for the determination of twelve azole antimicrobial drug residues in human plasma and urine. J. Chromatogr. B Anal. Technol. Biomed. Life Sci. 2017, 1040, 192-198. [CrossRef] [PubMed]

7. Mousa, B.A.; El-Kousy, N.M.; El-Bagary, R.I.; Mohamed, N.G. Stability indicating methods for the determination of some anti-fungal agents using densitometric and RP-HPLC methods. Chem. Pharm. Bull. 2008, 56, 143-149. [CrossRef] [PubMed] 
8. Zgoła-Grześkowiak, A.; Grześkowiak, T. Application of dispersive liquid-liquid microextraction followed by HPLC-MS/MS for the trace determination of clotrimazole in environmental water samples. J. Sep. Sci. 2013, 36, 2514-2521. [CrossRef] [PubMed]

9. Available online: https://www.fda.gov/files/drugs/published/Bioanalytical-Method-Validation-Guidancefor-Industry.pdf (accessed on 22 September 2020).

10. Kaza, M.; Karaźniewicz-Łada, M.; Kosicka, K.; Siemiątkowska, A.; Rudzki, P.J. Bioanalytical method validation: New FDA guidance vs. EMA guideline. Better or worse? J. Pharm. Biomed. Anal. 2019, 165, 381-385. [CrossRef] [PubMed]

11. Rifai, N.; Sakamoto, M.; Law, T.; Platt, O.; Mikati, M.; Armsby, C.C.; Brugnara, C. HPLC measurement, blood distribution, and pharmacokinetics of oral clotrimazole, potentially useful antisickling agent. Clin. Chem. 1995, 41, 387-391. [CrossRef] [PubMed]

12. Tawakkol, S.M.; Fayez, Y.M.; Fahmy, N.M.; Lotfy, H.M.; Shehata, M.A. Monitoring of Clotrimazole Degradation Pathway in Presence of its Co-formulated Drug. J. Chromatogr. Sci. 2019, 57, 518-527. [CrossRef] [PubMed]

13. Available online: https://www.ema.europa.eu/en/documents/scientific-guideline/draft-guideline-qualityequivalence-topical-products_en.pdf (accessed on 22 September 2020).

14. Yan, F.; Sun, M.; Hang, T.; Sun, J.; Zhou, X.; Deng, X.; Ge, L.; Qian, H.; Ya, D.; Huang, W. A rapid and sensitive UPLC-MS/MS method for determination of HZ08 in rat plasma and tissues: Application to a pharmacokinetic study of liposome injections. J. Pharm. Biomed. Anal. 2015, 102, 246-252. [CrossRef] [PubMed]

15. Weng, J.Y.; Song, M.; Hang, T.J.; Huang, W.L.; Du, Y. Pharmacokinetics of HZ08 in rats by liquid chromatography-tandem mass spectrometry. J. Chromatogr. B Anal. Technol. Biomed. Life Sci. 2007, 856, 29-34. [CrossRef] [PubMed]

16. Iqbal, D.N.; Ashraf, A.; Iqbal, M.; Nazir, A. Analytical method development and validation of hydrocortisone and clotrimazole in topical dosage form using RP-HPLC. Future J. Pharm. Sci. 2020, 6, 49. [CrossRef]

17. MuthuKumar, S.; Kathram, S.; Navanethan, J.; Selvakumar, D.; Banji, D. Method development and validation of rp-hplc method for simultaneous determination of clindamycinphosphate and clotrimazole in soft gelatinvaginal suppositories. Int. J. Pharm. Ther. 2013, 4, 270-275.

18. Ferreira, P.G.; Lima, C.G.S.; Noronha, L.L.; De Moraes, M.C.; Da Silva, F.; Vicosa, A.; Futuro, D.O.; Ferreira, V. Development of a Method for the Quantification of Clotrimazole and Itraconazole and Study of Their Stability in a New Microemulsion for the Treatment of Sporotrichosis. Molecules 2019, 24, 2333. [CrossRef] [PubMed]

19. American Hospital Formulary Service (AHFS) Drug Information. 2007. Available online: https://www. ahfsdruginformation.com/ (accessed on 22 September 2020).

Publisher's Note: MDPI stays neutral with regard to jurisdictional claims in published maps and institutional affiliations.

(C) 2020 by the authors. Licensee MDPI, Basel, Switzerland. This article is an open access article distributed under the terms and conditions of the Creative Commons Attribution (CC BY) license (http://creativecommons.org/licenses/by/4.0/). 